\title{
The attitudes of primary school children to breastfeeding and the effect of health education lectures
}

\author{
Mahmi Fujimori, ${ }^{1}$ Tassiane C. Morais, ${ }^{1}$ Eduardo L. França, ${ }^{2}$ \\ Olegário R. de Toledo, ${ }^{3}$ Adenilda C. Honório-França ${ }^{4}$
}

\begin{abstract}
Objective: To assess attitudes to breastfeeding among children in primary education and to evaluate the influence of educational lectures on their knowledge.

Methods: This was a cross-sectional study of 503 students of both sexes from the fourth to the eighth grades of five different schools. The children were divided into two groups: control $(n=215)$ and intervention $(n=288)$ in order to evaluate the influence of educational lectures. A questionnaire containing 30 questions about different features of breastfeeding was used for data collection. The intervention took the form of a 30-minute lecture, given at the schools.

Results: The lecture increased the number of schoolchildren who answered that breastmilk is most beneficial for infants $(p<0.05)$ and that breastfeeding is the most practical way of feeding babies $(p<0.05)$. There was a reduction in the number who would give supplementary feeding during the first month of life $(p<0.05)$ and also in how many would give a baby a pacifier $(p<0.05)$. After the intervention less than half of the girls would chose to breastfeed for 1 year or more (39.1\% in the control group vs. $43.2 \%$ in the intervention group); while the opposite was true of the males ( $54.7 \%$ in the control group vs. $51.7 \%$ in the intervention group). More of the boys ( $37.1 \%$ ) were able to cite specific advantages for mothers from breastfeeding when compared to the females (19.9\%).
\end{abstract}

Conclusions: The results indicate that lectures on health education, presented at schools, have a beneficial effect on breastfeeding knowledge, awareness and attitudes.

J Pediatr (Rio J). 2008;84(3):224-231: Breastfeeding, health education, schoolchildren.

\section{Introduction}

There has been increasing growth in breastfeeding rates in Brazil as a result of work to promote and support breastfeeding carried out by both governmental and non-governmental organizations. Nevertheless, median breastfeeding rates in Brazil continue to be below World Health Organization recommendations. The majority of interventions are carried out during the prenatal and postnatal periods, ${ }^{1}$ but these periods can only have a limited influence on individuals' decisions. ${ }^{2}$ There is therefore a clear need to develop other types of strategies that can contribute to raising breastfeeding awareness.
Opinions on infant feeding can be formed prior to pregnancy ${ }^{3}$ and even before adolescence, ${ }^{4}$ which suggests that promoting breastfeeding with individuals in a range of phases of human development could potentially be effective. ${ }^{5}$ If infants are provided with adequate information on breastfeeding at school, they will probably become adults with a greater capacity for choice ${ }^{6}$ and who do not accept modern and artificial practices without a fundamental critical evaluation. ${ }^{7}$

It takes several years to construct positive attitudes and beliefs about breastfeeding; it is therefore of fundamental importance to provide people with this type of information

1. Acadêmica de Farmácia, Instituto Universitário do Araguaia (Uniaraguaia), Universidade Federal de Mato Grosso (UFMT), Pontal do Araguaia, MT, Brazil.

2. Doutor. Professor adjunto, Uniaraguaia, UFMT, Pontal do Araguaia, MT, Brazil.

3. Mestre. Professor assistente, Departamento de Ciências Biológicas e da Saúde, Uniaraguaia, UFMT, Pontal do Araguaia, MT, Brazil.

4. Doutora. Professora adjunta, Uniaraguaia, UFMT, Pontal do Araguaia, MT, Brazil.

No conflicts of interest declared concerning the publication of this article.

Suggested citation: Fujimori M, Morais TC, França EL, de Toledo OR, Honório-França AC. The attitudes of primary school children to breastfeeding and the effect of health education lectures. J Pediatr (Rio J). 2008;84(3):224-231.

Manuscript received Dec 13 2007, accepted for publication Mar 262008.

doi:10.2223/JPED.1791 
constantly. ${ }^{8}$ Through teaching, the barriers limiting breastfeeding can be substituted by the concept that breastfeeding is a natural act. ${ }^{6,9,10}$

There are reports in the literature about the scarcity of information for young people on breastfeeding promotion. ${ }^{5}$ This indicates that it is not a common subject in schools.

The lack of positive exposure to breastfeeding, during childhood and adolescence, may be contributing to low breastfeeding rates. ${ }^{6}$ Schools are centers of teaching-learning, of shared experience and of growth where values for living acquired, ${ }^{11}$ which can be transmitted to families and communities. Studies that have assessed schoolchildren's knowledge about breastfeeding demonstrate that there is a need for measures to promote a more favorable attitude to the subject in schools, ${ }^{12}$ dealing with concepts that are not yet assimilated by the students. ${ }^{6}$ For these reasons, the objective of this study was to evaluate the attitudes to breastfeeding of schoolchildren in primary education and to evaluate the influence of educational lectures on their knowledge of the subject.

\section{Methods}

This was a cross sectional study of children of both sexes in the fourth to the eighth grades of primary schools in the urban area of the municipality of Barra do Garças (MT), Brazil. This municipality has 51 schools with classes at this level, 42 of which are public (five in rural areas and 37 in urban areas) and nine of which are private (all in urban areas).

Only three of the private schools had all of the grades of interest in this research and all were selected for study. Two private schools with the smallest number of students were combined to make a single cluster. Two public schools in urban areas were chosen by lots, in order to ensure that the number of children from public and private schools were as similar as possible. Lots were once more drawn in order to define which schools would be in each group: control group (one public school and two private schools) and intervention group (one public school and one private school). As a result of these choices, the number of children enrolled on the study was 503, with 215 allocated to the control group and 288 to the intervention group.

Free and informed consent forms were sent to the schools in order to determine the availability of the children to take part in the study. The researchers together with the schools' management explained the project to the teachers, who, in turn, were responsible for inviting the students in the intervention group to the lecture. Participation was voluntary and, irrespective of which group they were in, children only answered the questionnaires if they had returned consent forms signed by their parents or guardians. It was demonstrated that answers would be completely anonymous and that under no circumstances would identities be revealed.
A preliminary questionnaire containing 25 questions had been administered to 30 children of the same age group chosen for this study, with the intention of detecting any difficulties with understanding or variables that could cause bias. Based on the results of the pilot test, the necessary alterations were made to the questionnaire, the final version of which contained 30 questions, 25 with multiple choice answers and five open-ended questions. This instrument was made up of four sections dealing with distinct areas: (1) demographic information; (2) previous experience; (3) the students' knowledge, behavior and attitude; and (4) interest in the subject. Students in the intervention group were asked to ignore the lecture they had attended when replying to questions, "have you ever been given information about the importance of breastfeeding?" and "where did you receive this information?"

The questionnaires were administered at schools, between May and August of 2007, during morning sessions, which is when all of these students studied. The students in the control group took part in the research when their teachers were able to make available sufficient time to complete the questionnaires. The questionnaire was administered to the intervention group soon after they attended the lecture. Fourteen students who were already parents were excluded from the sample. Additionally, 38 students who were absent from school, 57 whose parents did not give authorization and two students who chose not to answer the questionnaire did not take part either.

The intervention consisted of a lecture, lasting $30 \mathrm{~min}-$ utes, delivered by the researchers themselves to groups containing an average of 30 students, making a total of 10 lectures. Visual aids were used, in the form of slides displayed using an image projector. The lectures included explanations about the practicality and reduced cost of breastfeeding when compared with artificial methods; the start and duration of exclusive and complemented breastfeeding and their significance to infant nutrition. Certain myths that are common in our culture, such as "weak milk," "milk is not enough" and "breastfeeding deforms the mother's breasts or causes stretch marks," were also dispelled. Furthermore, care was taken to get across to the students the negative influence of artificial teats and the importance of the support of parents and other family members in addition to the fact that breastfeeding is a natural process.

The sample was subdivided by sex for data analysis. Data were processed using Epi-Info ${ }^{\circledR}$ version $6.04 d$ to apply the Maentel-Haenszel chi-square test and Student's $t$ test. The results of analyses were considered significant when $p$ was less than $0.05(p<0.05)$.

This project was approved by the Research Ethics Committee at the Hospital Universitário Júlio Muller (HUJM), Universidade Federal de Mato Grosso (UFMT), protocol 341/ CEP-HUJM/07, of 8th August, 2007. 
Table 1 - Charactersitics of the students in the educational lecture intervention and control groups

\begin{tabular}{|c|c|c|c|}
\hline Characteristics & Control $(n=215)$ & Intervention $(n=288)$ & Total $(n=503)$ \\
\hline \multicolumn{4}{|l|}{ Sex } \\
\hline Male & $44.2 \%(95)$ & $47.6 \%(137)$ & $46.1 \%(232)$ \\
\hline Female & $55.8 \%(120)$ & $52.4 \%(151)$ & $53.9 \%(271)$ \\
\hline \multicolumn{4}{|l|}{ School } \\
\hline Private & $37.7 \%(81)$ & $60.7 \%(175)$ & $50.9 \%(256)$ \\
\hline Public & $62.3 \%(134)$ & $39.3 \%(113)$ & $49.1 \%(247)$ \\
\hline \multicolumn{4}{|l|}{ Grade } \\
\hline Fourth grade & $20.93 \%(45)$ & $14.6 \%(42)$ & $17.3 \%(87)$ \\
\hline Fifth grade & $29.3 \%(63)$ & $32.6 \%(94)$ & $31.2 \%(157)$ \\
\hline Sixth grade & $23.72 \%(51)$ & $18.4 \%(53)$ & $20.7 \%(104)$ \\
\hline Seventh grade & $15.4 \%(33)$ & $16.7 \%(48)$ & $16.1 \%(81)$ \\
\hline Eighth grade & $10.7 \%(23)$ & $17.7 \%(51)$ & $14.7 \%(74)$ \\
\hline \multicolumn{4}{|l|}{ Lives with } \\
\hline Mother only & $17.7 \%(38)$ & $18.4 \%(53)$ & $18.1 \%(91)$ \\
\hline Father only & $5.1 \%(11)$ & $2.4 \%(07)$ & $3.6 \%(18)$ \\
\hline Father and mother & $67.4 \%(145)$ & $70.1 \%(202)$ & $68.9 \%(347)$ \\
\hline Other relatives & $9.8 \%(21)$ & $9.1 \%(26)$ & $9.4 \%(47)$ \\
\hline
\end{tabular}

\section{Results}

Five hundred and three of the students were considered representative of the sample. Their mean age was 11.7 years and their distributions by school, grade, sex and people with whom they live are listed in Table 1.

There was a relationship between students who were breastfed as babies and intending to breastfeed in the future when mothers $(p<0.05)$. The students' previous experience of the subject is described in Table 2.

It was observed that $79.7 \%$ of the students showed an interest in being parents in future. A smaller number of female students $(67.9 \%)$ intended to have children, with $26.2 \%$ not giving a definite opinion on the subject. Approximately $96.0 \%$ of those students who intended to have children also intended to breastfeed them. When the boys were questioned, $98.3 \%$ expressed willingness to support their future wives in breastfeeding. There was a reservation with relation to breastfeeding in public, since $37.5 \%$ stated they would be uncomfortable with relation to their wives breastfeeding in public. The students' knowledge, attitudes and behavior with relation to the subject and also the effect of the intervention are shown in Table 3. When the students were asked about the advantages of human milk for babies, $29.3 \%$ of them replied that, "human milk contains all the nutrients that babies require," followed by, "breastmilk is the healthiest food for babies" (25.5\%). The supplementary foods that students most often stated they would give were water (27.6\%) and teas (19.5\%).
Of those students who stated that breastfeeding is also beneficial for mothers, $69.5 \%$ actually listed advantages relative to the health of babies in their replies; just $30.5 \%$ were able to provide specific advantages for mothers, and $58.8 \%$ of those who were able to do so were in the intervention group. Broken down by sex, $37.1 \%$ of the boys and $19.9 \%$ of the girls were able to describe these advantages. It is important to point out that the question about advantages was open and so the answers were provided spontaneously.

Students' interest in the subject of breastfeeding is shown in Table 4.

\section{Discussion}

In this study, students attended educational lectures about breastfeeding and it was observed that they demonstrated great interest in situations they experience in every day life. These data reinforce the hypothesis that educational measures aimed at the dissemination of breastfeeding as a cultural value to be acquired from childhood on, must be begun with school age children. ${ }^{13}$ Pro-breastfeeding programs face a certain difficulty in raising breastfeeding rates during the perinatal period due to prior internalization of negative concepts by adolescents. ${ }^{14}$ Nevertheless, these attitudes can be modified during adolescence and for this reason is it is also necessary to persist with the development of educational campaigns directed at adolescents. ${ }^{15}$

The majority of students had been exposed to breastfeeding in their own homes. Although these data do not quantify 
Table 2 - Students' previous experience of breastfeeding

\begin{tabular}{|c|c|c|c|}
\hline & Male $(n=232)$ & Female $(n=271)$ & Total (\%) \\
\hline \multicolumn{4}{|l|}{ Were you breastfed as a baby? } \\
\hline Yes & $85.3 \%(198)$ & $89.6 \%(243)$ & $87.7 \%(441)$ \\
\hline No & $3.4 \%(8)$ & $5.2 \%(14)$ & $4.4 \%(22)$ \\
\hline Don't remember & $11.2 \%(26)$ & $5.2 \%(14)$ & $7.9 \%(40)$ \\
\hline \multicolumn{4}{|l|}{$\begin{array}{l}\text { Have you ever seen a mother } \\
\text { breastfeeding? }\end{array}$} \\
\hline Yes & $45.7 \%(216)$ & $54.3 \%(257)$ & $94.1 \%(473)$ \\
\hline No & $53.3 \%(16)$ & $46.7 \%(14)$ & $5.9 \%(30)$ \\
\hline \multicolumn{4}{|l|}{ Where? } \\
\hline $\begin{array}{l}\text { At home or at a relative's } \\
\text { house }\end{array}$ & $42.4 \%(120)$ & $57.6 \%(163)$ & $59.8 \%(283)$ \\
\hline In public & $50.5 \%(96)$ & $49.5 \%(94)$ & $40.2 \%(190)$ \\
\hline \multicolumn{4}{|l|}{ Who did you see? } \\
\hline Mother or relative & $40.7 \%(114)$ & $59.3 \%(166)$ & $59.2 \%(280)$ \\
\hline A stranger & $52.8 \%(102)$ & $47.2 \%(91)$ & $40.8 \%(193)$ \\
\hline \multicolumn{4}{|l|}{$\begin{array}{l}\text { Have you ever been given } \\
\text { information about the } \\
\text { importance of breastfeeding? }\end{array}$} \\
\hline Yes & $82.3 \%(191)$ & $91.1 \%(247)$ & $87.1 \%(438)$ \\
\hline No & $17.7 \%(41)$ & $8.9 \%(24)$ & $12.9 \%(65)$ \\
\hline \multicolumn{4}{|l|}{$\begin{array}{l}\text { How did you receive this } \\
\text { information? }\end{array}$} \\
\hline From mother & $15.5 \%(29)$ & $34.3 \%(85)$ & $26.6 \%(116)$ \\
\hline School & $33.8 \%(65)$ & $25.5 \%(63)$ & $28.9 \%(127)$ \\
\hline Media & $42.3 \%(81)$ & $37.3 \%(92)$ & $39.3 \%(172)$ \\
\hline Others & $8.4 \%(16)$ & $2.9 \%(7)$ & $5.2 \%(23)$ \\
\hline
\end{tabular}

the intensity of exposure, they provide an indication that young people continued to have contact with breastfeeding at home. ${ }^{8}$ This fact contributes to a greater predisposition on the part of female students to breastfeed in the future. During the process of raising and educating their children, mothers provide the basis for the practice of breastfeeding through examples of life. ${ }^{16}$ In the same way that mothers can transmit positive behavior, they can also perpetuate long-held beliefs that have a negative influence on breastfeeding. ${ }^{12}$

With relation to future intentions, a larger number of male students expressed the intention to have children when compared with female students. Education in health and family planning and also concerns about their professional future may have an influence on the attitude of female students to being mothers when adults. They believe that they will be more negatively impacted professionally if they have children. The male students, in turn, may exhibit a tendency to believe that caring for babies is exclusively the responsibility of their mothers. More than $96.0 \%$ of the female students who expressed the intention to have children also intended to breastfeed. Irrespective of whether they were in the intervention or the control group, almost all of the male students intend to encourage their wives to breastfeed. It is worth pointing out that these results do not indicate that these students will be examples of breastfeeding success. The father's support during breastfeeding can increase the degree of maternal satisfaction with relation to the act of breastfeeding, ${ }^{17}$ and can also have positive effects on breastfeeding duration. ${ }^{18,19}$ Studies demonstrate that adolescent mothers with partners of a similar age are more likely to breastfeed than adolescent mothers with adult partners. ${ }^{20}$ Fathers' knowledge is strongly related to their inclination to support the practice. ${ }^{21}$ In addition to encouragement from the father, the relationship between the couple ${ }^{22}$ and support provided by other family members are also important for mothers to breastfeed their children. ${ }^{23}$

A study carried out by Greene et al. ${ }^{5}$ observed that a low number of boys were predisposed to encourage breastfeed- 
Table 3 - Students' knowledge, attitudes and behavior with relation to breastfeeding and the influence of an educational lecture

\begin{tabular}{|c|c|c|c|c|c|c|}
\hline & \multicolumn{3}{|c|}{ Males } & \multicolumn{3}{|c|}{ Females } \\
\hline & Control & Intervention & p* & Control & Intervention & p* \\
\hline \multicolumn{7}{|c|}{ Is breastfeeding good for babies? } \\
\hline Yes & $100.0 \%(95)$ & $100.0 \%(137)$ & & $99.2 \%(119)$ & $100.0 \%(151)$ & \\
\hline No & $0.0 \%(00)$ & $0.0 \%(00)$ & & $0.8 \%(01)$ & $0.0 \%(00)$ & \\
\hline \multicolumn{7}{|l|}{$\begin{array}{l}\text { Which type of milk is most } \\
\text { beneficial for babies? }\end{array}$} \\
\hline Powdered milk & $12.6 \%(12)$ & $2.9 \%(04)^{+}$ & $<0.05^{+}$ & $6.7 \%(8)$ & $2.6 \%(04)^{\ddagger}$ & $<0.05^{\ddagger}$ \\
\hline Breastmilk & $71.6 \%(68)$ & $92.7 \%(127)$ & & $70.8 \%(85)$ & $96.0 \%(145)$ & \\
\hline Both & $15.8 \%(15)$ & $4.4 \%(06)$ & & $22.5 \%(27)$ & $1.3 \%(02)$ & \\
\hline \multicolumn{7}{|l|}{$\begin{array}{l}\text { Is breastfeeding good for } \\
\text { mothers? }\end{array}$} \\
\hline Yes & $72.6 \%(69)$ & $86.9 \%(119)^{+}$ & $<0.05^{+}$ & $87.5 \%(105)$ & $92.7 \%(140)$ & \\
\hline No & $27.4 \%(26)$ & $13.1 \%(18)$ & & $12.5 \%(15)$ & $7.3 \%(11)$ & \\
\hline \multicolumn{7}{|c|}{$\begin{array}{l}\text { What's the most practical way of } \\
\text { feeding babies? }\end{array}$} \\
\hline Powdered milk & $23.2 \%(22)$ & $9.5 \%(13)^{+}$ & $<0.05^{+}$ & $15.0 \%(18)$ & $6.6 \%(10)^{\ddagger}$ & $<0.05^{\ddagger}$ \\
\hline Breastmilk & $55.8 \%(53)$ & $81.0 \%(111)$ & & $65.0 \%(78)$ & $83.4 \%(126)$ & \\
\hline Both & $21.0 \%(20)$ & $9.5 \%(13)$ & & $20.0 \%(24)$ & $10.0 \%(15)$ & \\
\hline \multicolumn{7}{|c|}{$\begin{array}{l}\text { Would you feed anything other } \\
\text { than mother's milk during the first } \\
\text { month of life? }\end{array}$} \\
\hline Yes & $24.2 \%(23)$ & $5.8 \%(08)^{+}$ & $<0.05^{+}$ & $35.8 \%(43)$ & $8.6 \%(13)^{\ddagger}$ & $<0.05^{\ddagger}$ \\
\hline No & $75.8 \%(72)$ & $94.2 \%(129)$ & & $64.2 \%(77)$ & $91.4 \%(138)$ & \\
\hline \multicolumn{7}{|c|}{$\begin{array}{l}\text { For how long should a mother } \\
\text { breastfeed her baby? }\end{array}$} \\
\hline Up to 1 month & $4.2 \%(04)$ & $0.7 \%(01)^{+}$ & $<0.05^{+}$ & $2.6 \%(03)$ & $0.7 \%(01)^{\ddagger}$ & $<0.05^{\ddagger}$ \\
\hline Up to 4 months & $11.6 \%(11)$ & $5.1 \%(07)$ & & $14.8 \%(18)$ & $3.4 \%(05)$ & \\
\hline Up to 6 months & $29.5 \%(28)$ & $42.3 \%(58)$ & & $43.5 \%(52)$ & $52.7 \%(78)$ & \\
\hline Up to 1 year or more & $54.7 \%(52)$ & $51.8 \%(71)$ & & $39.1 \%(47)$ & $43.2 \%(64)$ & \\
\hline \multicolumn{7}{|c|}{$\begin{array}{l}\text { Would you give a pacifier to a } \\
\text { baby? }\end{array}$} \\
\hline Yes & $58.9 \%(56)$ & $19.7 \%(27)^{+}$ & $<0.05^{+}$ & $40.8 \%(49)$ & $21.9 \%(33)^{\ddagger}$ & $<0.05^{\ddagger}$ \\
\hline No & $41.1 \%(39)$ & $80.3 \%$ (110) & & $59.2 \%(71)$ & $78.1 \%$ (118) & \\
\hline
\end{tabular}

* Chi-square test.

${ }^{+}$Comparing differences between the intervention and control groups for males.

₹ Comparing differences between the intervention and control groups for females.

ing. In this study, although a large number of boys were predisposed to encourage breastfeeding, $37.5 \%$ of them said that they would be embarrassed to see their wives breastfeeding in public and $30.6 \%$ of the female students reported the same sentiment. Boys more often see breasts as sexual organs, not taking into consideration the fact that their primary function is breastfeeding and so they have negative opinions of breastfeeding in public. ${ }^{12,24}$ This being so, schools could deal with the subject more intensely so that male students would come to see breastfeeding as a natural process. $6,9,10$

Health education programs are effective measures that can have a positive role in breastfeeding promotion. One intervention study using educational methods detected a reduction in negative attitudes with relation to breastfeeding. ${ }^{25}$ In another, with both prenatal and postnatal interventions, it was 
Table 4 - Student interest in breastfeeding

\begin{tabular}{|c|c|c|c|}
\hline & Male $(n=232)$ & Female $(n=271)$ & Total (\%) \\
\hline \multicolumn{4}{|l|}{$\begin{array}{l}\text { Have you ever been given information about the } \\
\text { importance of BF? }\end{array}$} \\
\hline Yes & $82.3 \%(191)$ & $91.1 \%(247)$ & $87.1 \%(438)$ \\
\hline No & $17.7 \%(41)$ & $8.9 \%(24)$ & $12.9 \%(65)$ \\
\hline \multicolumn{4}{|l|}{ Where did you receive this information?* } \\
\hline From mother & $15.5 \%(29)$ & $34.3 \%(85)$ & $26.6 \%(116)$ \\
\hline School & $33.8 \%(65)$ & $25.5 \%(63)$ & $28.9 \%(127)$ \\
\hline Media & $42.3 \%(81)$ & $37.3 \%(92)$ & $39.3 \%(172)$ \\
\hline Others & $8.4 \%(16)$ & $2,9 \%(7)$ & $5,2 \%(23)$ \\
\hline \multicolumn{4}{|l|}{ Do you believe: ${ }^{+}$} \\
\hline $\begin{array}{l}\text { Not everybody needs to receive information } \\
\text { about BF }\end{array}$ & $22.8 \%(53)$ & $9.2 \%(25)$ & $15.5 \%(78)$ \\
\hline $\begin{array}{l}\text { The advantages of BF should be discussed at } \\
\text { home }\end{array}$ & $45.7 \%(106)$ & $48.7 \%(132)$ & $47.3 \%(238)$ \\
\hline $\begin{array}{l}\text { Information about BF should be part of the school } \\
\text { curriculum }\end{array}$ & $58.6 \%(136)$ & $63.1 \%(171)$ & $61.0 \%(307)$ \\
\hline Teachers should actively promote BF & $39.6 \%(92)$ & $39.5 \%(107)$ & $39.6 \%(199)$ \\
\hline $\begin{array}{l}\text { Teachers need to receive more information about } \\
\text { BF }\end{array}$ & $41.4 \%(96)$ & $29.5 \%(80)$ & $34.9 \%(176)$ \\
\hline \multicolumn{4}{|l|}{ Would you like to learn more about the subject? } \\
\hline Yes & $80.6 \%(187)$ & $91.1 \%(247)$ & $86.3 \%(434)$ \\
\hline No & $19.4 \%(45)$ & $8.9 \%(24)$ & $13.7 \%(69)$ \\
\hline
\end{tabular}

$\mathrm{BF}=$ Breastfeeding.

* Comparing only students who received information according to gender.

+ More than one answer could be given.

found that the latter are less effective than interventions carried out prior to the birth. ${ }^{26}$ This could be an indication that earlier interventions may exert more positive effects than postnatal interventions. The results of this study indicated that the lecture had positive effects on the students' knowledge about the practicality of breastmilk in comparison with other methods of infant feeding and about pacifier use and complementary feeding at inappropriate ages. All of the students, irrespective of experimental group or sex, stated that breastfeeding brings benefits for babies, however they did not know specific advantages. In a study of adolescent mothers' knowledge and attitudes with relation to the subject, it was found that they have less knowledge of basic information. ${ }^{27}$

When asked about the advantages of breastfeeding for mothers, the males in the intervention group exhibited a greater capacity to assimilate this information during the lecture than the females in the same group. In answers to the open questions about the advantages for the mother's figure, the boys could actually cite these advantages, with values approximately double those observed for the girls. Possible reasons for the difference between the sexes could include the belief that the decision to breastfeed and the function of breastfeeding belong exclusively to women. ${ }^{2}$ The findings of this study demonstrated that male students can respond well to pro-breastfeeding programs that explain that the presence of the father can either help or hinder breastfeeding. These results are in agreement with others described in the literature, which demonstrate that educational strategies aimed at boys require special planning and assessment to be effective, since they exhibit greater resistance to accepting the subject. ${ }^{28}$

It was observed that a greater number of male students were favorable to prolonged breastfeeding, with the largest percentages of girls ( $43.5 \%$ control group and $52.7 \%$ intervention group) choosing the period of up to 6 months breastfeeding duration as correct. These results are possibly due to the fact that many campaigns emphasize breastfeeding up to 6 months of age and, very often, girls do not associate this with being the period of exclusive breastfeeding. It will also be observed that the intervention applied was not sufficient to make the majority of students believe that breastfeeding could be continued until 1 year of age or more. Similar results 
were found by Bottaro ${ }^{12}$ which demonstrates that this feature should be reinforced in breastfeeding promotion programs aimed at children and adolescents. These data reproduce what happens in adulthood, since a high number of mothers begin complementary foods too early. ${ }^{29}$

The great majority ( $87.1 \%$ ) of the students reported having been given some information about breastfeeding previously, with the media being the most common source, followed by information received at school. A study carried out by Forrester et al. ${ }^{9}$ showed that the majority of young people investigated reported that information about breastfeeding was received at home or via the media. Based on this, more initiatives in favor of breastfeeding should be made in the media with the intention of eliminating negative aspects and breaking down barriers that are prejudicial to breastfeeding. ${ }^{11}$ Around half of the students would like the subject to be discussed in their own homes. It was observed that male students received less information about breastfeeding at home. This is possibly because girls have a greater affinity and liberty to speak about breastfeeding and related subjects with their mothers. Examples of fathers who support and encourage their partners and cooperate with them during lactation phase may be important tools for boys to grow up with a positive mentality about breastfeeding and, as with girls, be able to mirror good examples. ${ }^{2}$

Around $80 \%$ of the female students and $91 \%$ of the male students stated they would like to learn more about breastfeeding. Just $28.9 \%$ of the students said they had been given information about the subject at school. It can therefore be perceived that there is a disparity between the students' interest in learning about the subject and the schools' interest in passing the information to their students. Furthermore, breastfeeding promotion reaches people of both sexes, in contrast with prenatal and postnatal interventions which generally only reach pregnant women and recently delivered mothers, rarely fathers. ${ }^{28}$

There is a report in the literature that the effect of interventions with students may continue for at least 3 months, although there is the possibility that the effects will reduce or even disappear over time in the absence of reinforcement. ${ }^{12}$ Adding the subject to the school curriculum would be an important measure for achieving this reinforcement.

Analysis of the overall results indicates that a health education lecture can be of use for increasing students' knowledge and also for changing behavior with relation to breastfeeding. Promotion of positive beliefs about the subject among young people is an important step towards increasing breastfeeding in the future. These actions may translate into better rates, since, as has been widely described in the literature, greater knowledge represents greater capacity of choice and predisposition to breastfeed. It is essential to point out that the male individuals studied here, in contrast with what has been described in other studies, exhibited significant perception in assimilating the subject presented to them. In certain aspects, this perception surpassed that of the females, which is a fact that could be used as an important factor in the formation of generations of more conscious fathers, leading to a different culture of co-participation and increasing breastfeeding rates in Brazil.

\section{Acknowledgements}

The authors would like to thank the pharmacy undergraduate students Aline B. Cavalcante, Ericka K. R. Lopes, Silvia R. B. Cavalcante, Larissa N. Ribeiro and Veronice S. Barbosa from the Instituto Universitário do Araguaia for their invaluable help during their lectures and to Dr. Maria Celeste Saad Guirra for her valuable help in correcting the Portuguese of the original text.

\section{References}

1. Swanson V, Power K, Kaur B, Carter H, Shepherd K. The impact of knowledge and social influences on adolescents' breast-feeding beliefs and intentions. Public Health Nutr. 2006; 9:297-305.

2. Goulet C, Lampron A, Marcil I, Ross L. Attitudes and subjective norms of male and female adolescents toward breastfeeding. J Hum Lact. 2003;19:402-10.

3. Losch M, Dungy CI, Russel D, Dusdieker LB. Impact of attitudes on maternal decisions regarding infant feeding. J Pediatr. 1995; 126:507-14.

4. Ineichen B, Pierce M, Lawrenson R. Teenage mothers as breastfeeders: attitudes and behaviour. J Adolesc. 1997;20: 505-9.

5. Greene J, Stewart-Knox B, Wright M. Feeding preferences and attitudes to breastfeeding and its promotion among teenagers in Nothern Ireland. J Hum Lact. 2003;19:57-65.

6. Nakamura SS, Veiga KF, Ferrarese SR, Martinez FE. Percepção e conhecimento de meninas escolares sobre o aleitamento materno. J Pediatr (Rio J). 2003;79:181-8.

7. Xavier CC, Viana MR, Silva NC, Chaves SV. O aleitamento materno e o livro didático do $1^{\circ}$ grau. J Pediatr (Rio J). 1987;63: 178-9.

8. Danner S. How do we influence the breastfeeding decision? Birth. 1991;18:227-8.

9. Forrester IT, Wheelock G, Warren AP. Assessment of student's attitudes toward breastfeeding. J Hum Lact. 1997; 13:33-7.

10. Connolly C, Kelleher CC, Becker G, Friel S, Gabhainn SN. Attitudes of young men and woman to breastfeeding. I Med J. 1998;91: 88-9.

11. Pelicione MC, Torres AL. A escola promotora de Saúde. São Paulo: Faculdade de Saúde Pública, Universidade de São Paulo; 1999.

12. Bottaro SM. Avaliação de estratégia para promoção do aleitamento materno em escolas do ensino fundamental [dissertação]. Portal Alegre, RS: Universidade Federal do Rio Grande do Sul; 2006. 
13. Terrengui LC. Avaliação de um programa educativo sobre amamentação aplicado a escolares do ensino fundamental [dissertação]. São Paulo, SP: Universidade de Santo Amaro; 2003.

14. Leffler D. US high school age girls may be receptive to breastfeeding promotion. J Hum Lact. 2000;16:36-40.

15. Reifsnider E, Eckart D. Prenatal breastfeeding education: Its effect on breastfeeding among WIC participants. J Hum Lact. 1997;13:121-25.

16. Primo CC, Caetano, LC. A decisão de amamentar da nutriz: percepção de sua mãe. J Pediatr. 1999;75:449-55.

17. Jordan $P L$, Wall VR. Supporting the father when an infant is breastfed. J Hum Lact. 1993;9:31-4.

18. Pisacane A, Continisio GI, Aldinucci M, D'Amora S, Continisio P. A controlled trial of the father's role in breastfeeding promotion. Pediatrics. 2005;116; e494-8.

19. Arora S, McJunkin C, Wehrer J, Kuhn P. Major factors influencing breastfeeding rates: mother's perception of father's attitude and milk supply. Pediatrics. 2000;106:E67.

20. Harner HM, McCarter-Spaulding D. Teenage mothers and breastfeeding: does paternal age make a difference? J Hum Lact. 2004;20:404-8.

21. Rivera Alvarado I, Vázquez García V, Dávila Torres RR, Parrilla Rodríguez AM. Exploratory study: breastfeeding knowledge, attitudes towards sexuality and breastfeeding, and disposition towards supporting breastfeeding in future Puerto Rican male parents. P R Health Sci J. 2006;25:337-41.

22. Falceto OG, Giugliani ER, Fernandes CL. Couples' relationships and breastfeeding: is there an association? J Hum Lact. 2004; 20:46-55.
23. Mahgoub SE, Bandeke T, Nnyepi M. Breastfeeding in Botswana: practices, attitudes, patterns, and the socio-cultural factors affecting them. J Trop Pediatr. 2002;48:195-9.

24. Li R, Fridinger F, Grummer-Strawn L. Public perceptions on breastfeeding constraints. J Hum Lact. 2002;18:227-35.

25. Ryser FG. Breastfeeding attitudes, intention, and initiation in low-income women: the effect of the best start program. J Hum Lact. 2004;20:300-5.

26. de Oliveira MI, Camacho LA, Tedstone AE. Extending breastfeeding duration through primary care: a systematic review of prenatal and postnatal interventions. J Hum Lact. 2001; 17:326-43.

27. Martens PJ. The effect of breastfeeding education on adolescent beliefs and attitudes: a randomized school intervention in the Canadian Ojibwa community of Sagkeeng. J Hum Lact. 2001; 187:245-55.

28. Brunken GS, Silva SM, França GV, Escuder MM, Venâncio SI. Risk factors for early interruption of exclusive breastfeeding and late introduction of complementary foods among infants in midwestern Brazil. J Pediatr (Rio J). 2006:82:445-51.

29. Bella H. Are Saudi female college students prepared for successful breastfeeding? J R Soc Health. 1997; 117:387-92.

Correspondence:

Adenilda C. Honório-França

Instituto Universitário do Araguaia (UFMT)

Rodovia MT 100, km 3,5 s/no

CEP 78698-000 - Pontal do Araguaia, MT - Brazil

Tel.: +55 (66) 3402.1110

E-mail: adenilda@ufmt.br 